\title{
African American patients with gout: efficacy and safety of febuxostat vs allopurinol
}

\author{
Alvin F Wells ${ }^{1 *}$, Patricia A MacDonald ${ }^{2}$, Solomon Chefo ${ }^{2}$ and Robert L Jackson ${ }^{2}$
}

\begin{abstract}
Background: African Americans are twice as likely as Caucasians to develop gout, but they are less likely to be treated with urate-lowering therapy (ULT). Furthermore, African Americans typically present with more comorbidities associated with gout, such as hypertension, obesity, and renal impairment. We determined the efficacy and safety of ULT with febuxostat or allopurinol in African American subjects with gout and associated comorbidities and in comparison to Caucasian gout subjects.
\end{abstract}

Methods: This is a secondary analysis of the 6 -month Phase 3 CONFIRMS trial. Eligible gouty subjects with baseline serum urate $(s \cup A) \geq 8.0 \mathrm{mg} / \mathrm{dL}$ were randomized 1:1:1 to receive febuxostat $40 \mathrm{mg}$, febuxostat $80 \mathrm{mg}$, or allopurinol (300 mg or $200 \mathrm{mg}$ depending on renal function) daily. All subjects received gout flare prophylaxis. Primary efficacy endpoint was the proportion of subjects in each treatment group with $\mathrm{s} U A<6.0 \mathrm{mg} / \mathrm{dL}$ at the final visit. Additional endpoints included the proportion of subjects with mild or with moderate renal impairment who achieved a target sUA $<6.0 \mathrm{mg} / \mathrm{dL}$ at final visit. Adverse events (AEs) were recorded throughout the study.

Results: Of the 2,269 subjects enrolled, 10.0\% were African American and 82.1\% were Caucasian. African American subjects were mostly male (89.5\%), obese (BMI $\geq 30 \mathrm{~kg} / \mathrm{m}^{2} ; 67.1 \%$ ), with mean baseline sUA of $9.8 \mathrm{mg} / \mathrm{dL}$ and mean duration of gout of 10.4 years. The proportions of African American subjects with a baseline history of diabetes, renal impairment, or cardiovascular disease were significantly higher compared to Caucasians $(p<0.001)$. ULT with febuxostat $80 \mathrm{mg}$ was superior to both febuxostat $40 \mathrm{mg}(p<0.001)$ and allopurinol $(p=0.004)$.

Febuxostat $40 \mathrm{mg}$ was comparable in efficacy to allopurinol. Significantly more African American subjects with mild or moderate renal impairment achieved $\mathrm{s} U A<6.0 \mathrm{mg} / \mathrm{dL}$ in the febuxostat 80 group than in either the febuxostat $40 \mathrm{mg}$ or allopurinol group $(p<0.05)$. Efficacy rates in all treatment groups regardless of renal function were comparable between African American and Caucasian subjects, as were AE rates.

Conclusions: In African American subjects with significant comorbidities, febuxostat $80 \mathrm{mg}$ is significantly more efficacious than either febuxostat 40 mg or allopurinol 200/300 mg. Febuxostat was well tolerated in this African American population.

Please see related article: http://www.biomedcentral.com/1741-7015/10/15

\section{Background}

The rate of gout in the United States has been on the rise and increases with age, in both men and women [1-3]. African Americans make up roughly $13 \%$ of the US population [4], and are twice as likely as Caucasians to develop gout $[5,6]$. In a prospective cohort study, 571 Caucasian and 352 African American young men were followed for a median duration of 29 years [5]. The

\footnotetext{
*Correspondence: a.f.wells@att.net

'Rheumatology and Immunotherapy Center, 4225 W. Oakwood Park Court; Franklin, WI 53132, USA

Full list of author information is available at the end of the article
}

cumulative incidence of gout in these 2 cohorts was $5.8 \%$ and $10.9 \%$, respectively. Yet, African Americans represent only $10 \%$ of the patients treated for gout [7]. Moreover, when they are treated, they are less likely to receive urate-lowering therapy (ULT) [7]. Furthermore, African Americans typically present with higher rates of comorbidities, such as hypertension, obesity, and renal impairment [8], and have higher rates of diuretic use compared to Caucasians [9], all of which have been independently associated with hyperuricemia and gout [10].

\section{Biomed Central}

(c) 2012 Wells et al; licensee BioMed Central Ltd. This is an Open Access article distributed under the terms of the Creative Commons Attribution License (http://creativecommons.org/licenses/by/2.0), which permits unrestricted use, distribution, and reproduction in any medium, provided the original work is properly cited. 
Gout is characterized by hyperuricemia (serum urate concentration [sUA] exceeding $6.8 \mathrm{mg} / \mathrm{dL}$, the limit of urate solubility) and acute and chronic consequences of monosodium urate crystal deposition, such as tophi and gout flares [11]. Long-term management of chronic gout with ULT focuses on achieving and maintaining sUA in a sub-saturating range $(<6.0 \mathrm{mg} / \mathrm{dL})$ with the goal of dissolving monosodium urate crystals and decreasing the body pool of uric acid $[12,13]$. ULT for up to 5 years leads to the elimination of acute flares and reduction in the size and number of tophi present $[14,15]$.

Available ULT options in the US include xanthine oxidase (XO) inhibitors allopurinol and febuxostat, and probenecid, a uricosuric. Allopurinol, which is the mainstay of chronic gout management [16], requires dose adjustments in gout patients with renal impairment [17], which may lead to reduced efficacy [18]. Febuxostat is a selective, non-purine analog XO inhibitor [19] for the treatment of chronic hyperuricemia in patients with gout [20]. Data from 3 comparative, blinded, randomized controlled trials (RCTs) have demonstrated the superior efficacy of febuxostat $80 \mathrm{mg}$ daily compared with both the commonly prescribed dose of allopurinol (300 mg) [17] and placebo [21-23]. In addition, both approved doses of febuxostat, $80 \mathrm{mg}$ and $40 \mathrm{mg}$, are significantly more efficacious than allopurinol $(p<0.001$ and $p=0.012$, respectively) in achieving the therapeutic target sUA in subjects with mild-to-moderate renal impairment [23].

There are no data from prospective RCTs specifically exploring ULT efficacy and safety in African Americans with gout. The objective of this post hoc subanalysis of the CONFIRMS trial [23], the largest ULT RCT to date, was to examine the urate-lowering efficacy and safety of febuxostat and allopurinol in hyperuricemic African American subjects with gout in comparison to Caucasian subjects.

\section{Methods}

The 6-month CONFIRMS (NCT\# 00430248) trial enrolled male and female subjects 18 to 85 years of age with a diagnosis of gout (defined by American Rheumatology Association preliminary criteria [24]) and hyperuricemia ( $\mathrm{sUA} \geq 8.0 \mathrm{mg} / \mathrm{dL}$ ). Approval was obtained from Quorum Review Institutional Review Board, Seattle, WA. Subjects provided written, informed consent and Health Insurance Portability and Accountability Act authorization prior to any study-related procedure. This study was conducted with respect for the individual participating subjects according to the Declaration of Helsinki, the ICH Harmonised Tripartite Guideline for GCP, and all applicable local regulations. Exclusion criteria included secondary hyperuricemia, xanthinuria, severe renal impairment (estimated creatinine clearance
[eCLcr] $<30 \mathrm{~mL} / \mathrm{min}$, calculated by Cockcroft-Gault formula corrected for ideal body weight $[25,26]$ ), alanine aminotransferase and aspartate aminotransferase values $>1.5$ times the upper limit of normal, consumption of > 14 alcoholic drinks per week or a history of alcoholism or drug abuse within 5 years, or medical condition that would interfere with treatment, safety, or adherence to the study protocol. In addition, subjects with known hypersensitivity to febuxostat, allopurinol, naproxen, any other non-steroidal anti-inflammatory agents, aspirin, lansoprazole, colchicine, or any components of these drugs formulations were excluded.

Subjects were randomized 1:1:1 to receive a daily dose of either febuxostat $40 \mathrm{mg}$, febuxostat $80 \mathrm{mg}$ (Uloric ${ }^{\circledR}$; Takeda Global Research \& Development Center, Inc; Deerfield, IL), or allopurinol (Apotex; Weston, FL, USA). Subjects randomized to allopurinol were to receive $300 \mathrm{mg}$ daily if baseline renal function was normal (eCLcr $\geq 90 \mathrm{~mL} / \mathrm{min}$ ) or mildly impaired (eCLcr 60 to $<90 \mathrm{~mL} / \mathrm{min}$ ); subjects with moderate renal impairment (eCLcr 30 to $<60 \mathrm{~mL} / \mathrm{min}$ ) were to receive 200 mg daily.

Throughout the 6-month treatment period, subjects received prophylaxis for gout flares, self-administering either colchicine (Westward Pharmaceutical Corporation; Eatontown, NJ) $0.6 \mathrm{mg}$ daily, or naproxen (Westward Pharmaceutical Corporation) $250 \mathrm{mg}$ twice daily. Subjects with eCLcr $<50 \mathrm{~mL} / \mathrm{min}$ were not to receive naproxen. All subjects receiving naproxen prophylaxis also received lansoprazole $15 \mathrm{mg}$ daily (Takeda Global Research \& Development Center, Inc).

The primary efficacy endpoint of CONFIRMS was the proportion of subjects in each treatment group who achieved a target sUA $<6.0 \mathrm{mg} / \mathrm{dL}$ at final visit [23]. In the primary CONFIRMS analysis of the total cohort $(\mathrm{N}$ $=2,269)$, non-inferiority of febuxostat $40 \mathrm{mg}$ compared to allopurinol $300 / 200 \mathrm{mg}$ dose was demonstrated. Binomial 95\% confidence intervals (CIs) were calculated for the difference between the 2 groups in achieving the primary efficacy endpoint. Non-inferiority was declared if the lower limit of the $95 \%$ CI for difference in the proportion of subjects achieving an sUA $<6.0 \mathrm{mg} / \mathrm{dL}$ at the last visit was greater than $-10 \%$. The difference between the febuxostat $40 \mathrm{mg}$ group $(45.2 \%)$ and the allopurinol group (42.1\%) was 3.1\% (95\% CI: -1.9\% $8.1 \%)$, thus demonstrating non-inferiority [23]. Efficacy comparisons between treatment groups were made using Fisher's exact test (two-tailed, 0.05 significance level. Additional efficacy endpoints were the proportion of subjects in each treatment group with mild and with moderate renal impairment who achieved a target sUA $<6.0 \mathrm{mg} / \mathrm{dL}$ at final visit. Pairwise comparisons were made between treatment groups with Fisher's exact test. The objectives of our current analyses were to assess 
the primary and additional efficacy endpoints and safety among African American subjects and compare these results with those observed in the subgroup of Caucasian subjects enrolled in the CONFIRMS trial.

All treatment-emergent adverse events (AEs) were recorded using Medical Dictionary for Regulatory Activities (MedDRA). Gout flares were not considered AEs and were reported separately.

Statistical analyses of the achievement of the efficacy endpoints for each treatment group have been previously described in detail [23]. In addition, to determine statistically significant differences between African American and Caucasian subjects for baseline characteristics of age, body mass index (BMI), baseline sUA, and years with gout, analysis of variance was used; for all other categorical baseline variables, Fisher's exact test was used. In addition, Fisher's exact test was used to determine statistical significant differences between the proportions of African American and Caucasian subjects within each treatment group who achieved the primary and additional efficacy endpoints, and differences in rates of AEs between African American and Caucasian subjects.

\section{Results}

Of the 2,269 subjects who enrolled in the CONFIRMS trial, 228 (10.0\%) were African American and 1,863 (82.1\%) were Caucasian. Fifty-two (22.8\%) and 329 (17.7\%) African Americans and Caucasian subjects, respectively, discontinued from the study prematurely (Figure 1). The most common primary reason for premature discontinuation among African American subjects was lost to follow-up $(\mathrm{n}=22 ; 9.6 \%)$, while AEs were the most frequent primary reason for Caucasians ( $\mathrm{n}=149 ; 8.0 \%)$. Compliance with therapy ( $\geq 90 \%$ compliant), calculated as the number of capsules taken divided by the number of days on drug, was lower among African Americans compared to Caucasians; $72.4 \%$ vs $82.1 \%$, respectively. When analyzed by treatment group, compliance ( $\geq 90 \%$ ) for African American subjects in the febuxostat $40 \mathrm{mg}$, febuxostat $80 \mathrm{mg}$, and allopurinol treatment groups was $66.3 \%, 76.9 \%$, and $74.6 \%$, respectively, while it was $82.4 \%, 82.2 \%$, and $81.6 \%$, respectively, for Caucasian subjects.

At baseline, compared to the Caucasian subgroup, the African American subgroup had significantly more women $(10.5 \%$ vs $5.1 \% ; p<0.001)$, higher mean BMI $\left(34.0 \mathrm{~kg} / \mathrm{m}^{2}\right.$ vs $\left.32.8 \mathrm{~kg} / \mathrm{m}^{2} ; p=0.006\right)$, higher mean sUA $(9.8 \mathrm{mg} / \mathrm{dL}$ vs $9.5 \mathrm{mg} / \mathrm{dL} ; p<0.001)$, and lower mean duration of gout (10.4 years vs 11.8 years; $p=0.030$ ). In addition, the proportions of subjects with a history of diabetes, renal impairment, or cardiovascular disease at baseline were significantly higher among African Americans compared to Caucasians $(p<0.001$; Table 1$)$.
The primary efficacy endpoint of this analysis, sUA < $6.0 \mathrm{mg} / \mathrm{dL}$ at final visit, was achieved by $34.9 \%, 66.7 \%$, and $41.8 \%$ of African American subjects in the febuxostat $40 \mathrm{mg}$, febuxostat $80 \mathrm{mg}$, and allopurinol 200/300 mg groups, respectively. Febuxostat $80 \mathrm{mg}$ was significantly more efficacious than both febuxostat $40 \mathrm{mg}(p<0.001)$ and allopurinol 200/300 mg ( $p=0.004)$. Similarly, among Caucasian subjects, significantly higher proportions of subjects in the febuxostat $80 \mathrm{mg}$ group (68.4\%) achieved sUA $<6.0 \mathrm{mg} / \mathrm{dL}$ compared to those in the febuxostat 40 mg group (46.8\%; $p<0.001)$ and in the allopurinol 200/ $300 \mathrm{mg}$ group $(43.3 \% ; p<0.001)$. No statistical difference was observed in the urate-lowering efficacy rate between febuxostat $40 \mathrm{mg}$ and allopurinol 200/300 $\mathrm{mg}$ in either the African American or Caucasian subgroup. Figure 2A provides comparisons of the achievement of the primary endpoint between African American and Caucasian subjects within each treatment group. Achievement of the primary efficacy endpoint was comparable between African American and Caucasian subjects when compared within treatment groups for either febuxostat $80 \mathrm{mg}$ or allopurinol 200/300 mg. Although febuxostat was effective in African Americans, significantly less African American subjects achieved sUA $<6.0 \mathrm{mg} / \mathrm{dL}$ with febuxostat $40 \mathrm{mg}$ than did Caucasian subjects $(p=0.046)$.

In both African American and Caucasian subjects with mild renal impairment, the urate-lowering efficacy of febuxostat $80 \mathrm{mg}$ was greater than that of either febuxostat $40 \mathrm{mg}$ ( $p=0.002$ in African Americans; $p<0.001$ in Caucasians) or allopurinol 200/300 mg ( $p=0.016$ in African Americans; $p<0.001$ in Caucasians). The same pattern was also observed in subjects with moderate renal impairment. Figures $2 \mathrm{~B} / \mathrm{C}$ provide comparisons in efficacy between African American and Caucasian subjects with mild or moderate renal impairment within each treatment group; efficacy rates between African American and Caucasian subjects within each treatment group were comparable.

In the febuxostat $40 \mathrm{mg}$, febuxostat $80 \mathrm{mg}$, and allopurinol 200/300 mg groups, 30\%, 31\%, and 30\% of African Americans, respectively, and $30 \%, 31 \%$, and $25 \%$ of Caucasians, respectively, required treatment for acute gout flares during the 6 months of the study.

Overall rates of AEs were comparable across treatment groups for both African American and Caucasian subjects. At least $1 \mathrm{AE}$ was reported in the febuxostat $40 \mathrm{mg}$, febuxostat $80 \mathrm{mg}$, and allopurinol $200 / 300 \mathrm{mg}$ groups by $45.8 \%$, $60.3 \%$, and $44.8 \%$ of African American subjects, respectively, and by $57.3 \%, 53.4 \%$, and $58.7 \%$ of Caucasian subjects, respectively. Table 2 lists the most frequently reported AEs for African American and Caucasian subjects.

Overall, rates of serious AEs were comparable across treatment groups in African American subjects as well as in the Caucasian subjects. Among African American subjects, $3.6 \%, 3.8 \%$, and $4.5 \%$ in the febuxostat $40 \mathrm{mg}$, 


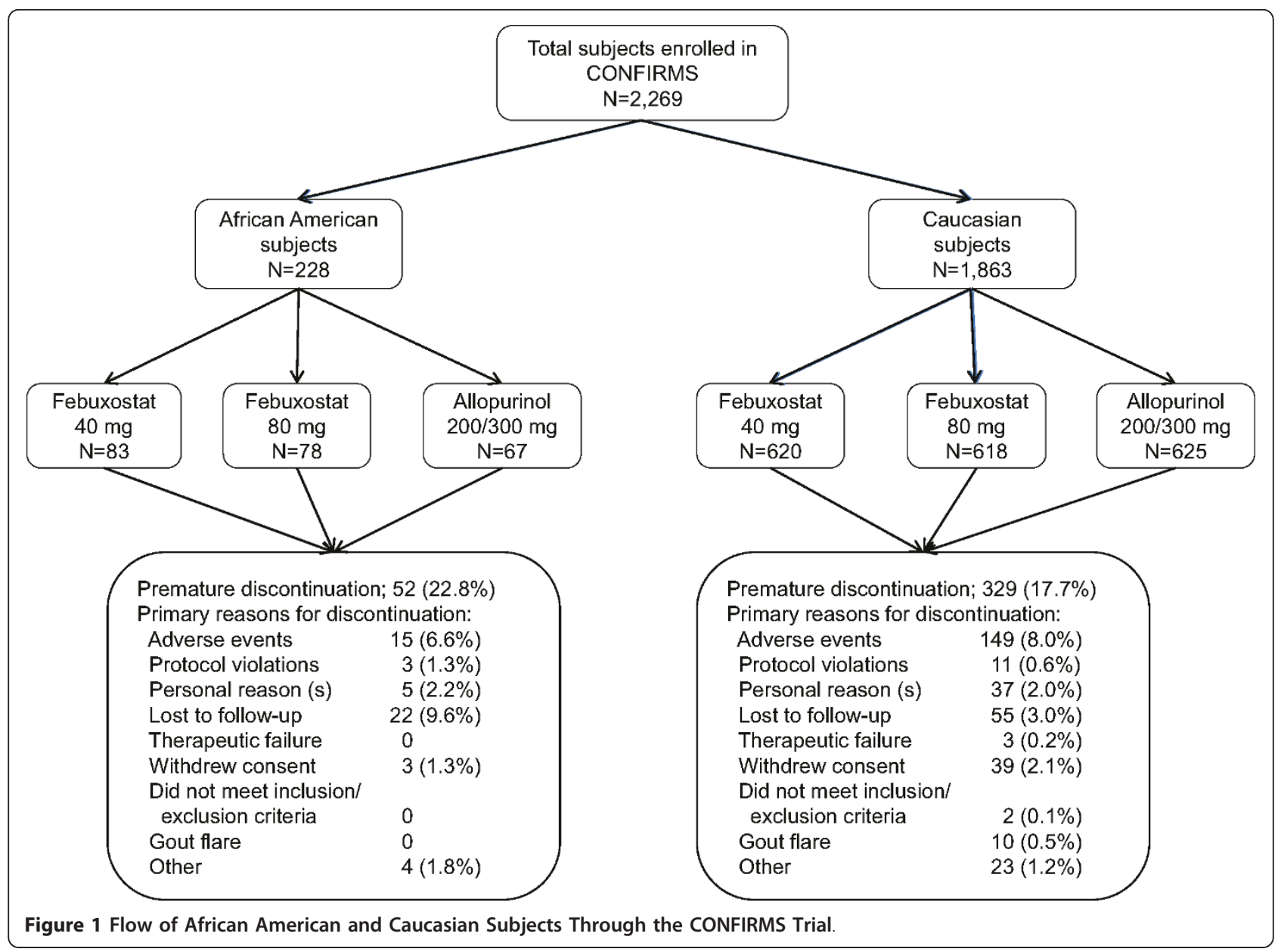

febuxostat $80 \mathrm{mg}$, and allopurinol 200/300 mg groups, respectively, reported at least 1 serious $\mathrm{AE}$, while $2.3 \%$, $3.9 \%$, and $4.3 \%$ of Caucasian subjects, respectively, reported at least 1 serious AE. One (1.2\%) African American subject, in the febuxostat $40 \mathrm{mg}$ group, reported a cardiac serious AE. Among Caucasian subjects, cardiac serious AEs were reported by 3 (0.5\%), 5 $(0.8 \%)$, and $5(0.8 \%)$ subjects in the febuxostat $40 \mathrm{mg}$, febuxostat $80 \mathrm{mg}$, and allopurinol 200/300 mg groups, respectively. Five subjects died during the CONFIRMS trial [23]-2 were African American (1 from sudden death and the other from necrotizing sepsis after surgery for lung carcinoma) and 3 were Caucasian (1 hypertensive heart disease, 1 anaphylactic shock from fire ant stings, and 1 brain edema and chronic pulmonary lung disease). No death was considered by investigators to be related to study drug.

\section{Discussion}

Differences in the efficacy and safety of various drugs in different racial groups have been well documented and can be attributed to differing rates of comorbid conditions, concomitant medication use, and underlying genetic variations in the enzymes involved in drug metabolism [27]. For example, dosing adjustments for warfarin are recommended in African American patients due to decreased metabolism of the drug, which can lead to increased risk for bleeding. Clinical and genetic components that may affect warfarin metabolism in African Americans include age, weight, cerebrovascular disease, and the presence of certain variants of the hepatic isoenzyme cytochrome P450 (CYP) 2C9, the primary metabolizer of warfarin [28]. Febuxostat is extensively metabolized in the liver by conjugation via uridine diphosphate glucuronosyltransferase (UGT) enzymes, including UGT1A1, UGT1A3, UGT1A9, and UGT2B7, and, to a much lesser extent, oxidation via CYP1A2, $2 \mathrm{C} 8,2 \mathrm{C} 9$, and non-P450 enzymes [20]. Different gene variants for UGT1A1, UGT1A9, and CYP2C9 have been identified in African Americans vs Caucasians [29-31]. However, based on our results in this limited number of African American subjects, these genetic variants do not appear to affect the metabolism of febuxostat in such a way that would interfere with its efficacy. 
Table 1 Comparison of Baseline Demographics and Characteristics Between African American and Caucasian Subjects in the CONFIRMS Trial

\begin{tabular}{|c|c|c|c|}
\hline Variable & African American $\mathrm{N}=228$ & Caucasian $\mathrm{N}=1,863$ & $p$ value $^{a}$ \\
\hline \multicolumn{4}{|l|}{ Gender, $n$ (\%) } \\
\hline Male & $204(89.5)$ & $1,768(94.9)$ & $<0.001$ \\
\hline Female & $24(10.5)$ & $95(5.1)$ & \\
\hline \multicolumn{4}{|l|}{ Age (years) } \\
\hline Mean \pm SD & $53.2 \pm 10.45$ & $53.0 \pm 11.80$ & 0.799 \\
\hline \multicolumn{4}{|l|}{ Body Mass Index $\left(\mathrm{kg} / \mathrm{m}^{2}\right)$} \\
\hline Mean \pm SD & $34.0 \pm 7.47$ & $32.8 \pm 6.09$ & 0.006 \\
\hline \multicolumn{4}{|l|}{ Alcohol Use, $n(\%)$} \\
\hline Non-/Ex-drinker & $88(38.6)$ & $563(30.2)$ & 0.010 \\
\hline Drinker (1-14 drinks/week) & $140(61.4)$ & $1,300(69.8)$ & \\
\hline \multicolumn{4}{|l|}{ Tobacco Use, $n(\%)$} \\
\hline Non-/Ex-tobacco User & $177(77.6)$ & $1,528(82.0)$ & 0.107 \\
\hline Tobacco User & $51(22.4)$ & $335(18.0)$ & \\
\hline \multicolumn{4}{|l|}{ Serum Urate $(\mathrm{mg} / \mathrm{dL})$} \\
\hline Mean \pm SD & $9.8 \pm 1.24$ & $9.5 \pm 1.16$ & $<0.001$ \\
\hline \multicolumn{4}{|l|}{ Years with Gout } \\
\hline Mean \pm SD & $10.4 \pm 8.28$ & $11.8 \pm 9.49$ & 0.030 \\
\hline \multicolumn{4}{|l|}{ Tophi Present, $n$ (\%) } \\
\hline No & $169(74.1)$ & $1,482(79.5)$ & 0.058 \\
\hline Yes & $59(25.9)$ & $381(20.5)$ & \\
\hline \multicolumn{4}{|l|}{ Renal Function, ${ }^{\mathbf{b}} n(\%)$} \\
\hline Moderately Impaired & $69(30.3)$ & $299(16.0)$ & $<0.001$ \\
\hline Mildly Impaired & $109(47.8)$ & $884(47.5)$ & \\
\hline Normal & $50(21.9)$ & $680(36.5)$ & \\
\hline \multicolumn{4}{|l|}{ Medical History, $n(\%)$} \\
\hline Any cardiovascular disease & $170(74.6)$ & $1,024(55.0)$ & $<0.001$ \\
\hline Hypertension & $165(72.4)$ & $937(50.3)$ & $<0.001$ \\
\hline Coronary artery disease & $25(11.0)$ & $161(8.6)$ & 0.245 \\
\hline Cardiac arrhythmia & $19(8.3)$ & $202(10.8)$ & 0.245 \\
\hline Diabetes & $57(25.0)$ & $229(12.3)$ & $<0.001$ \\
\hline Hypercholesterolemia & $19(8.3)$ & $130(7.0)$ & 0.454 \\
\hline Hyperlipidemia & $83(36.4)$ & $776(41.7)$ & 0.128 \\
\hline Use of low-dose aspirin ( $\leq 325 \mathrm{mg}$ daily) & $40(17.5)$ & $343(18.4)$ & 0.749 \\
\hline
\end{tabular}

${ }^{a} p$ values determined from analysis of variance model for age, body mass index, baseline serum urate, and years with gout, and by Fisher's exact test for all other variables.

${ }^{\mathrm{b}}$ Moderate baseline renal impairment: estimated creatinine clearance (eCLcr) 30 to $<60 \mathrm{~mL} / \mathrm{min}$; mild baseline renal impairment: eCLcr 60 to $<90 \mathrm{~mL} / \mathrm{min}$; normal: eCLcr $\geq 90 \mathrm{~mL} / \mathrm{min}$.

The higher rates of gout noted in the African American population $[5,6]$ have been attributed to high rates of comorbid conditions associated with increased risk for gout [10], such as diabetes, hypertension, obesity, and renal disease [8]. Along with clinical differences that may contribute to increased risk for developing gout, identification of underlying genetic differences in the various enzymes and transporters involved in purine metabolism and urate renal excretion could shed further light on why African Americans are affected with gout at higher rates. For example, a number of renal urate transporters and their genes have been identified. Variants of these genes influence sUA. While some of these genetic variants strongly influence sUA in both Caucasians and African Americans, others are more specifically associated with one race or the other [32-34].

There is a growing body of evidence that both hyperuricemia and gout increase the risk for the development and/or progression of renal dysfunction, cardiovascular disease, hypertension, metabolic syndrome, and diabetes [35-40], and all-cause and cardiovascular-related mortality $[41,42]$. In addition, the evidence suggests a disparity between African Americans and Caucasians. In the Atherosclerosis Risk in Communities Study, a prospective epidemiological cohort study, increasing sUA as a continuous variable-after adjusting for age, baseline 


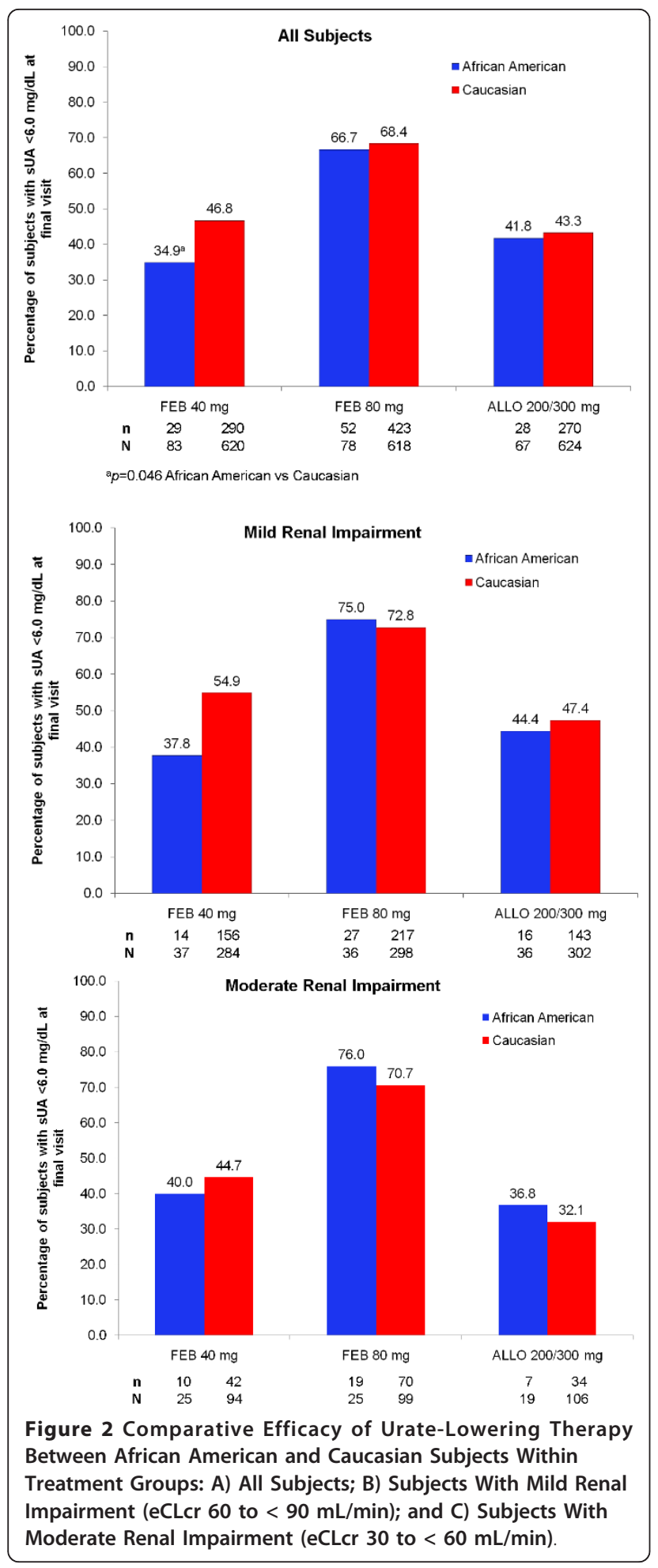

blood pressure, BMI, renal function, diabetes, and smoking-was shown to significantly increase the risk for the development of hypertension in African Americans, but not for Caucasians, regardless of concomitant medication use [43]. In another such study, each unit increase in sUA was associated with a higher risk for cardiovascular mortality in African American men and women compared to their Caucasian counterparts [44].

Proper management of the underlying hyperuricemia of gout is necessary for the proven reduction in the clinical manifestations of the disease, including gout flares and tophi [14,15,45-47]. Although not approved for such use, treatment with allopurinol or febuxostat has also been shown to ameliorate renal damage induced by hyperuricemia in rats $[48,49]$, and to stabilize or even improve renal function in humans [50-53]. A recent study in humans has also demonstrated the cardiovascular-protective impact of lowering sUA levels [35]. Therefore, proper management of African American gout patients goes beyond the acute treatment of flares, tophi, or kidney stones and incorporates effective reduction and maintenance of sUA to target levels of $<6.0$ $\mathrm{mg} / \mathrm{dL}$.

While the clinical benefits of reducing sUA long-term likely extend beyond relief from gout, providing optimum management to African American gout patients may be challenging. Data from the National Ambulatory Medical Care Survey reveal that of 3.9 million outpatient visits with a gout diagnosis that occurred in the US during 2002, only $10 \%$ were made by African Americans vs $82 \%$ by Caucasians [7]. Caucasians with a gout visit were more likely to have private insurance $(46 \%)$ compared to African Americans (11\%; p < 0.001) and, importantly, African Americans were less likely than Caucasians to receive ULT with allopurinol (odds ratio [OR] 0.18; 95\% CI, 0.04-0.78; $p=0.02$ ) [7]. In addition, African American patients with gout are more likely to be non-adherent with ULT than Caucasian patients (OR 1.86; 95\% CI, 1.52-2.27) [54]. Interestingly, we observed in this analysis that the African American subjects were 3-times more likely to be lost to follow up than the Caucasian subjects ( $9.6 \%$ vs $3.0 \%$, respectively) and less adherent with therapy ( $72.4 \%$ vs $82.1 \%$, respectively).

There are no published studies specifically examining racial disparities in the diagnosis and management of gout. Therefore possible explanations for low rates of gout diagnosis despite higher risk, lower use of ULT, and lower compliance with therapy among African Americans compared to Caucasians can only be inferred from other chronic diseases. In a 2002 report on ethnic disparities in arthritis and musculoskeletal diseases [55], Jordan et al. attributed some disparities to ethnic differences in access to care, care-seeking behavior, and utilization of care. According the 2010 National Healthcare Disparities Report [56], healthcare quality and access continue to be suboptimal for minority and low-income groups. Perceived provider discrimination, which is higher among minorities, can lead to delay in seeking health care [57]. There are noted racial differences in 
Table 2 Most Frequently Reported Adverse Events and Elevated Serum Liver Function Tests in African American and Caucasian Subjects

\begin{tabular}{|c|c|c|c|}
\hline & African American $\mathrm{N}=228$ & Caucasian $\mathrm{N}=1863$ & $p$ value $^{\mathrm{a}}$ \\
\hline Total subjects reporting $\geq 1 \mathrm{AE}, n$ (\%) & $115(50.4)$ & $1052(56.5)$ & 0.090 \\
\hline \multicolumn{4}{|l|}{ Most frequently reported $\mathrm{AEs}, n(\%)$} \\
\hline Liver function analyses & $8(3.5)$ & $141(7.6)$ & 0.020 \\
\hline Upper respiratory tract infections & $15(6.6)$ & $141(7.6)$ & 0.689 \\
\hline Diarrhea & $10(4.4)$ & $128(6.9)$ & 0.202 \\
\hline Musculoskeletal and connective tissue signs and symptoms & $9(3.9)$ & $89(4.8)$ & 0.739 \\
\hline Joint related signs and symptoms & $7(3.1)$ & $69(3.7)$ & 0.851 \\
\hline \multicolumn{4}{|l|}{ Elevated liver function tests, $n / N(\%)$} \\
\hline \multicolumn{4}{|l|}{ ALT } \\
\hline$\geq 2 X \cup L N$ & $5 / 206(2)$ & 172/1737 (10) & $<0.001$ \\
\hline$\geq 3 \times \cup L N$ & $1 / 206(<1)$ & $50 / 1737(3)$ & 0.037 \\
\hline \multicolumn{4}{|l|}{ AST } \\
\hline$\geq 2 X$ ULN & 8/206 (4) & $93 / 1736$ (5) & 0.505 \\
\hline$\geq 3 X$ ULN & $3 / 206(1)$ & 24/1736 (1) & 0.760 \\
\hline
\end{tabular}

$\mathrm{AE}=$ adverse event; ALT = alanine aminotransferase; $\mathrm{AST}=$ aspartate aminotransferase; ULN = upper limit of normal

${ }^{a} p$ values are from Fisher's exact test

AEs are reported by MedDRA High Level Term. Most frequent events are those occurring in at least 3 percent of African American subjects.

treatment preferences for rheumatoid arthritis; African American patients attach greater importance to the risks of toxicity and less importance to the likelihood of benefit than their Caucasian counterparts [58,59]. Similarly, among patients with at least moderately severe osteoarthritis, African Americans were significantly less likely than Caucasians to perceive the benefit of total joint arthroplasty and more likely to recognize barriers to the procedure [60]. Based on just the above small sampling of the literature, it is likely that the underlying reasons for racial disparities in gout are multifactorial and require investigation.

ULT with febuxostat $80 \mathrm{mg}$ was significantly better than either febuxostat $40 \mathrm{mg}$ or allopurinol 200/300 mg in the African American cohort of hyperuricemic gout subjects with high rates of comorbidities. This was also observed in the Caucasian cohort and reflects the overall results of the CONFIRMS trial [23]. Similarly, among both African Americans and Caucasians with mild or moderate renal impairment, febuxostat $80 \mathrm{mg}$ was significantly better at achieving sUA $<6.0 \mathrm{mg} / \mathrm{dL}$ compared to either febuxostat $40 \mathrm{mg}$ or allopurinol 200/300 mg.

When the efficacy of each treatment group was compared between African American and Caucasian subjects, the only significant difference observed was in the febuxostat $40 \mathrm{mg}$ treatment group, with lower efficacy observed in African American subjects in the overall cohort ( $34.9 \%$ vs $46.8 \% ; p=0.046)$. One plausible explanation for this observed difference may be the noted difference in compliance with treatment. Within the febuxostat $40 \mathrm{mg}$ group, Caucasian subjects had a considerably higher compliance rate $(82.4 \%)$ than their African American counterparts (66.3\%). This difference was greater than those observed in the other 2 treatment groups. In addition, a large numerical difference was observed in subjects with mild renal impairment (37.8\% vs $54.9 \%$ ) but this did not reach statistical significance $(p=0.055)$. The lack of significant difference is likely due to the small number of African American subjects. In addition, no significant differences were observed between African American and Caucasian subjects with mild or with moderate renal impairment in the efficacy of febuxostat $80 \mathrm{mg}$ or allopurinol 200/300 mg. In each treatment group the percentages of African American and Caucasian subjects that required treatment for gout flares were comparable. Flare rates during initial ULT correlate with the extent of sUA decrease [61], therefore similar rates reflect comparable efficacy between the two groups. Along with comparable efficacy, ULT with either dose of febuxostat or allopurinol 200/300 mg was well-tolerated by both African Americans and Caucasian subjects.

Limitations of this subanalysis include its post-hoc nature and the low number of African Americans enrolled in the CONFIRMS trial compared to Caucasians. Despite the fact that they develop gout at higher rates than Caucasians [5,6], in the CONFIRMS trial, along with other ULT RCTs, African Americans comprised $\leq 10 \%$ of the study population [21-23]. Underrepresentation of African Americans in the febuxostat clinical trials is not unique to the enrollment patterns observed for the majority of Phase 3 clinical intervention trials conducted in the US and reflects the continued 
hurdles faced by trial investigators in recruiting minority populations [62]. However, the data reported here represents the first report of ULT efficacy and safety in African American gout patients. Additional studies incorporating greater numbers of minorities are needed to confirm our results.

\section{Conclusions}

ULT is equally efficacious in African American and Caucasian gout patients. For African American gout patients with mild or moderate renal impairment, febuxostat $80 \mathrm{mg}$ is significantly more effective at lowering sUA to $<6.0 \mathrm{mg} / \mathrm{dL}$ than febuxostat $40 \mathrm{mg}$ or the commonly prescribed doses of allopurinol (200 or 300 mg) [17].

\section{Acknowledgements}

The CONFIRMS study (NCT\# 00430248) was fully funded by TAP Pharmaceutical Products, Inc, which is now a part of Takeda Global Research \& Development Center, Inc, Deerfield, IL. Assistance in manuscript preparation was provided by Meryl Gersh, PhD, of AlphaBioCom, LLC, in King of Prussia, PA, and was funded by Takeda Global Research \& Development Center, Inc.

\section{Author details}

${ }^{1}$ Rheumatology and Immunotherapy Center, 4225 W. Oakwood Park Court; Franklin, WI 53132, USA. ${ }^{2}$ Takeda Global Research and Development Center, Inc, One Takeda Parkway, Deerfield, IL 60015, USA.

\section{Authors' contributions}

Alvin F. Wells was involved in the acquisition of data, data analysis and interpretation, and preparation of the manuscript. Patricia A. MacDonald, Solomon Chefo, and Robert L. Jackson were involved in study concept and design, acquisition of data, data analysis and interpretation, and preparation of the manuscript. All authors provided final approval to submit the manuscript. The study sponsor, Takeda Global Research \& Development Center, Inc, was involved in the study design, protocols, subject recruitment, data collections, and analyses.

\section{Competing interests}

Alvin F. Wells has served as a consultant for Takeda Global Research \& Development Center, Inc, Abbott Laboratories, Amgen, Inc, Bristol-Myers Squibb Company, Contactor, Inc, Eli Lilly and Company, GlaxoSmithKline, Pfizer, Inc, Wyeth Pharmaceuticals, and Genetech, Inc. Patricia A. MacDonald, Solomon Chefo, and Robert L. Jackson are all employees of Takeda Global Research \& Development Center, Inc, and were employees of TAP Pharmaceutical Products, Inc, at the time of the study conduct.

Received: 28 June 2011 Accepted: 9 February 2012

Published: 9 February 2012

\section{References}

1. Arromdee E, Michet CJ, Crowson CS, O'Fallon WM, Gabriel SE: Epidemiology of gout: is the incidence rising? J Rheumatol 2002, 29:2403-2406.

2. Wallace $K L$, Riedel $A A$, Joseph-Ridge $N$, Wortmann R: Increasing prevalence of gout and hyperuricemia over 10 years among older adults in a managed care population. J Rheumatol 2004, 31:1582-1587.

3. Lawrence RC, Felson DT, Helmick CG, Arnold LM, Choi H, Deyo RA, Gabriel S, Hirsch R, Hochberg MC, Hunder GG, Jordan JM, Katz JN, Kremers HM, Wolfe F: Estimates of the prevalence of arthritis and other rheumatic conditions in the United States. Part II. Arthritis Rheum 2008, 58:26-35.

4. United States Census Bureau. Table 3. Annual Estimates of the Resident Population by Sex, Race, and Hispanic Origin for the United States: April 1,
2000 to July 1, 2009 (NC-EST2009-03) 2010, Available at: http://www.census. gov/popest/national/asrh/NC-EST2009-srh.html. Accessed February 14, 2011.

5. Hochberg MC, Thomas J, Thomas DJ, Mead L, Levine DM, Klag MJ: Racial differences in the incidence of gout. The role of hypertension. Arthritis Rheum 1995, 38:628-632.

6. Lawrence RC, Helmick CG, Arnett FC, Deyo RA, Felson DT, Giannini EH, Heyse SP, Hirsch R, Hochberg MC, Hunder GG, Liang MH, Pillemer SR, Steen VD, Wolfe F: Estimates of the prevalence of arthritis and selected musculoskeletal disorders in the United States. Arthritis Rheum 1998, 41:778-799.

7. Krishnan $E$, Lienesch $D$, Kwoh CK: Gout in ambulatory care settings in the United States. J Rheumatol 2008, 35:498-501.

8. National Center for Health Statistics. Health, United States, 2009: With special feature on medical technology. Hyattsville, MD: Centers for Disease Control. U.S. Department of Health and Human Services; 2010

9. Batson B, Belletti D, Wogen J: Effect of African American race on hypertension management: a real-world observational study among 28 US physician practices. Ethn Dis 2010, 20:409-415.

10. Choi HK, Mount DB, Reginato AM: Pathogenesis of gout. Ann Intern Med 2005, 143:499-516.

11. Terkeltaub RA: Clinical practice. Gout. N Engl J Med 2003, 349:1647-1655.

12. Becker MA, Chohan S: We can make gout management more successful now. Curr Opin Rheumatol 2008, 20:167-172.

13. Shoji A, Yamanaka $H$, Kamatani N: A retrospective study of the relationship between serum urate level and recurrent attacks of gouty arthritis: evidence for reduction of recurrent gouty arthritis with antihyperuricemic therapy. Arthritis Rheum 2004, 51:321-325.

14. Becker MA, Schumacher HR, MacDonald PA, Lloyd E, Lademacher C: Clinical efficacy and safety of successful long-term urate lowering with febuxostat or allopurinol in subjects with gout. J Rheumatol 2009, 36:1273-1278.

15. Schumacher HR Jr, Becker MA, Lloyd E, MacDonald PA, Lademacher C: Febuxostat in the treatment of gout: 5-yr findings of the FOCUS efficacy and safety study. Rheumatology (Oxford) 2009, 48:188-194.

16. Bartels EC, Matossian GS: Gout: six-year follow-up on probenecid (benemid) therapy. Arthritis Rheum 1959, 2:193-202.

17. Sarawate CA, Brewer KK, Yang W, Patel PA, Schumacher HR, Saag KG, Bakst AW: Gout medication treatment patterns and adherence to standards of care from a managed care perspective. Mayo Clin Proc 2006, 81:925-934.

18. Zhang W, Doherty M, Bardin T, Pascual E, Barskova V, Conaghan P, Gerster J, Jacobs J, Leeb B, Liote F, McCarthy G, Netter P, Nuki G, PerezRuiz F, Pignone A, Pimentao J, Punzi L, Roddy E, Uhlig T, ZimmermannGorska I: EULAR evidence based recommendations for gout. Part II: Management. Report of a task force of the EULAR Standing Committee for International Clinical Studies Including Therapeutics (ESCISIT). Ann Rheum Dis 2006, 65:1312-1324.

19. Dalbeth N, Kumar S, Stamp L, Gow P: Dose adjustment of allopurinol according to creatinine clearance does not provide adequate control of hyperuricemia in patients with gout. J Rheumatol 2006, 33:1646-1650.

20. Uloric $^{\circledR}$ Full Prescribing Information. Deerfield, IL: Takeda Pharmaceuticals North America, Inc:; 2011

21. Becker MA, Schumacher HR Jr, Wortmann RL, MacDonald PA, Eustace D, Palo WA, Streit J, Joseph-Ridge N: Febuxostat compared with allopurinol in patients with hyperuricemia and gout. N Engl J Med 2005, 353:2450-2461.

22. Schumacher HR Jr, Becker MA, Wortmann RL, Macdonald PA, Hunt B, Streit J, Lademacher C, Joseph-Ridge N: Effects of febuxostat versus allopurinol and placebo in reducing serum urate in subjects with hyperuricemia and gout: a 28-week, phase III, randomized, double-blind, parallel-group trial. Arthritis Rheum 2008, 59:1540-1548.

23. Becker MA, Schumacher HR, Espinoza LR, Wells AF, Macdonald P, Lloyd E, Lademacher C: The urate-lowering efficacy and safety of febuxostat in the treatment of the hyperuricemia of gout: the CONFIRMS trial. Arthritis Res Ther 2010, 12:R63.

24. Wallace SL, Robinson H, Masi AT, Decker JL, McCarty DJ, Yu TF: Preliminary criteria for the classification of the acute arthritis of primary gout. Arthritis Rheum 1977, 20:895-900.

25. Cockcroft DW, Gault MH: Prediction of creatinine clearance from serum creatinine. Nephron 1976, 16:31-41. 
26. Robert S, Zarowitz BJ, Peterson EL, Dumler F: Predictability of creatinine clearance estimates in critically ill patients. Crit Care Med 1993, 21:1487-1495

27. Belle DJ, Singh H: Genetic factors in drug metabolism. Am Fam Physician 2008, 77:1553-1560.

28. Cavallari LH, Langaee TY, Momary KM, Shapiro NL, Nutescu EA, Coty WA, Viana MA, Patel SR, Johnson JA: Genetic and clinical predictors of warfarin dose requirements in African Americans. Clin Pharmacol Ther 2010, 87:459-464.

29. Villeneuve L, Girard H, Fortier LC, Gagne JF, Guillemette C: Novel functional polymorphisms in the UGT1A7 and UGT1A9 glucuronidating enzymes in Caucasian and African-American subjects and their impact on the metabolism of 7-ethyl-10-hydroxycamptothecin and flavopiridol anticancer drugs. J Pharmacol Exp Ther 2003, 307:117-128.

30. Kaniwa N, Kurose K, Jinno H, Tanaka-Kagawa T, Saito Y, Saeki M, Sawada J, Tohkin M, Hasegawa R: Racial variability in haplotype frequencies of UGT1A1 and glucuronidation activity of a novel single nucleotide polymorphism 686C > T (P229L) found in an African-American. Drug Metab Dispos 2005, 33:458-465.

31. Dickmann $L$, Rettie $A E$, Kneller MB, Kim RB, Wood AJ, Stein CM, Wilkinson GR, Schwarz Ul: Identification and functional characterization of a new CYP2C9 variant (CYP2C9*5) expressed among African Americans. Mol Pharmacol 2001, 60:382-387.

32. Dehghan A, Kottgen A, Yang Q, Hwang SJ, Kao WL, Rivadeneira F, Boerwinkle E, Levy D, Hofman A, Astor BC, Benjamin EJ, van Duijn CM, Witteman JC, Coresh J, Fox CS: Association of three genetic loci with uric acid concentration and risk of gout: a genome-wide association study. Lancet 2008, 372:1953-1961.

33. Rule AD, de Andrade M, Matsumoto M, Mosley TH, Kardia S, Turner ST: Association between SLC2A9 transporter gene variants and uric acid phenotypes in African American and white families. Rheumatology (Oxford) 2010

34. Charles BA, Shriner D, Doumatey A, Chen G, Zhou J, Huang H, Herbert A, Gerry NP, Christman MF, Adeyemo A, Rotimi CN: A genome-wide association study of serum uric acid in African Americans. BMC Med Genomics 2011, 4:17

35. Krishnan E: Inflammation, oxidative stress and lipids: the risk triad for atherosclerosis in gout. Rheumatology (Oxford) 2010, 49:1229-1238.

36. Kutzing MK, Firestein BL: Altered uric acid levels and disease states. J Pharmacol Exp Ther 2008, 324:1-7.

37. Krishnan E, Baker JF, Furst DE, Schumacher HR: Gout and the risk of acute myocardial infarction. Arthritis Rheum 2006, 54:2688-2696.

38. Whelton $A$ : Current and future therapeutic options for the management of gout. Am J Ther 2010, 17:402-417.

39. Dehghan A, van Hoek M, Sijbrands EJ, Hofman A, Witteman JC: High serum uric acid as a novel risk factor for type 2 diabetes. Diabetes Care 2008, 31:361-362.

40. De Vera MA, Rahman MM, Bhole V, Kopec JA, Choi HK: Independent impact of gout on the risk of acute myocardial infarction among elderly women: a population-based study. Ann Rheum Dis 2010, 69:1162-1164.

41. Choi HK, Curhan G: Independent impact of gout on mortality and risk for coronary heart disease. Circulation 2007, 116:894-900.

42. Krishnan E, Svendsen K, Neaton JD, Grandits G, Kuller LH: Long-term cardiovascular mortality among middle-aged men with gout. Arch Intern Med 2008, 168:1104-1110.

43. Mellen PB, Bleyer AJ, Erlinger TP, Evans GW, Nieto FJ, Wagenknecht LE, Wofford MR, Herrington DM: Serum uric acid predicts incident hypertension in a biethnic cohort: the atherosclerosis risk in communities study. Hypertension 2006, 48:1037-1042.

44. Fang J, Alderman MH: Serum uric acid and cardiovascular mortality the NHANES I epidemiologic follow-up study, 1971-1992. National Health and Nutrition Examination Survey. Jama 2000, 283:2404-2410.

45. Perez-Ruiz F, Atxotegi J, Hernando I, Calabozo M, Nolla JM: Using serum urate levels to determine the period free of gouty symptoms after withdrawal of long-term urate-lowering therapy: a prospective study. Arthritis Rheum 2006, 55:786-790.

46. Perez-Ruiz F, Calabozo M, Pijoan Jl, Herrero-Beites AM, Ruibal A: Effect of urate-lowering therapy on the velocity of size reduction of tophi in chronic gout. Arthritis Rheum 2002, 47:356-360.
47. Perez-Ruiz F, Liote F: Lowering serum uric acid levels: what is the optimal target for improving clinical outcomes in gout? Arthritis Rheum 2007, 57:1324-1328

48. Sanchez-Lozada LG, Tapia E, Soto V, Avila-Casado C, Franco M, Wessale JL, Zhao $L$, Johnson RJ: Effect of febuxostat on the progression of renal disease in 5/6 nephrectomy rats with and without hyperuricemia. Nephron Physiol 2008, 108:p69-78.

49. Sanchez-Lozada LG, Tapia E, Soto V, Avila-Casado C, Franco M, Zhao L, Johnson RJ: Treatment with the xanthine oxidase inhibitor febuxostat lowers uric acid and alleviates systemic and glomerular hypertension in experimental hyperuricaemia. Nephrol Dial Transplant 2008, 23:1179-1185.

50. Whelton A, Macdonald PA, Zhao L, Hunt B, Gunawardhana L: Renal function in gout: long-term treatment effects of febuxostat. $J$ Clin Rheumatol 2011, 17:7-13.

51. Gibson T, Rodgers V, Potter C, Simmonds HA: Allopurinol treatment and its effect on renal function in gout: a controlled study. Ann Rheum Dis 1982, 41:59-65.

52. Kanbay M, Ozkara A, Selcoki $Y$, Isik B, Turgut F, Bavbek N, Uz E, Akcay A, Yigitoglu R, Covic A: Effect of treatment of hyperuricemia with allopurinol on blood pressure, creatinine clearance, and proteinuria in patients with normal renal functions. Int Urol Nephrol 2007, 39:1227-1233.

53. Siu YP, Leung KT, Tong MK, Kwan TH: Use of allopurinol in slowing the progression of renal disease through its ability to lower serum uric acid level. Am J Kidney Dis 2006, 47:51-59.

54. Solomon DH, Avorn J, Levin R, Brookhart MA: Uric acid lowering therapy: prescribing patterns in a large cohort of older adults. Ann Rheum Dis 2008, 67:609-613.

55. Jordan JM, Lawrence R, Kington R, Fraser P, Karlson E, Lorig K, Liang MH: Ethnic health disparities in arthritis and musculoskeletal diseases: report of a scientific conference. Arthritis Rheum 2002, 46:2280-2286.

56. 2010 National Healthcare Disparities Report. Agency for Healthcare Research and Quality. 2011, AHRQ Publication No. 11-0005. [http://www. ahrq.gov/qual/qrdr10.htm].

57. Lee C, Ayers SL, Kronenfeld JJ: The association between perceived provider discrimination, healthcare utilization and health status in racial and ethnic minorities. Ethn Dis 2009, 19:330-337.

58. Constantinescu F, Goucher S, Weinstein A, Smith W, Fraenkel L: Understanding why rheumatoid arthritis patient treatment preferences differ by race. Arthritis Rheum 2009, 61:413-418.

59. Constantinescu F, Goucher S, Weinstein A, Fraenkel L: Racial disparities in treatment preferences for rheumatoid arthritis. Med Care 2009, 47:350-355.

60. Ang DC, Monahan PO, Cronan TA: Understanding ethnic disparities in the use of total joint arthroplasty: application of the health belief model. Arthritis Rheum 2008, 59:102-108.

61. Becker MA, MacDonald PA, Hunt BJ, Lademacher C, Joseph-Ridge N: Determinants of the clinical outcomes of gout during the first year of urate-lowering therapy. Nucleosides Nucleotides Nucleic Acids 2008, 27:585-591.

62. Shaya FT, Gbarayor CM, Huiwen Keri Y, Agyeman-Duah M, Saunders E: A perspective on African American participation in clinical trials. Contemp Clin Trials 2007, 28:213-217.

\section{Pre-publication history}

The pre-publication history for this paper can be accessed here: http://www.biomedcentral.com/1471-2474/13/15/prepub

doi:10.1186/1471-2474-13-15

Cite this article as: Wells et al:: African American patients with gout: efficacy and safety of febuxostat vs allopurinol. BMC Musculoskeletal Disorders 2012 13:15. 